\title{
The Influence of Surrounding Ground Floor Facilities on the Use of Privately Owned Public Spaces in Seoul
}

\author{
Bonwoo Koo, Yumi Lee* \\ Department of Landscape Architecture, Graduate School of Environmental Studies, Seoul National University, \\ Seoul, South Korea \\ Email: *yumil@snu.ac.kr
}

Received 12 May 2015; accepted 27 June 2015; published 30 June 2015

Copyright (C) 2015 by authors and Scientific Research Publishing Inc.

This work is licensed under the Creative Commons Attribution International License (CC BY). http://creativecommons.org/licenses/by/4.0/

(c) (7) 0pen Access

\begin{abstract}
Seoul's privately owned public space (POPS) initiative has achieved quantitative success since its introduction in the early 1990s. However, POPSs have been frequently criticized for failing to correspond with the urban context in which they are created and are thus often underused. Association between surrounding urban context and the use of POPS is acknowledged, but specific elements of the urban context associated with the use of POPS and the extent of association are unclear. In this study, the relationship between constituent elements of 48 POPSs including the surrounding ground floor facility use and the use of those spaces in Seoul's central business district was measured by multiple regression analysis. The results present empirical evidence of a substantial relationship between assembly, mercantile, and business facilities on ground floors of surrounding buildings and the use of POPS. As the surrounding ground floor facility use showed an overriding relationship with the use of POPS that possibly overshadowed the influence of secondary determinants, the 48 POPSs were divided into two groups: those surrounded by commercial facilities and those surrounded by business facilities. The use of POPSs surrounded by commercial facilities was associated with additional variables including the proximity to transit stations and crosswalks. Models using the sample of POPSs surrounded by business facilities were not statistically significant. Based on these results, this paper emphasizes the importance of creating POPSs in connection with desirable surrounding facilities. This study also suggests that anticipation of the usage patterns of POPSs and establishment of guidelines supporting those patterns may be viable by investigating preexisting urban contexts.
\end{abstract}

\section{Keywords}

Privately Owned Public Space, Surrounding Facility, Usage Pattern, Multiple Regression Analysis

\footnotetext{
${ }^{*}$ Corresponding author.
}

How to cite this paper: Koo, B. and Lee, Y. (2015) The Influence of Surrounding Ground Floor Facilities on the Use of Privately Owned Public Spaces in Seoul. Journal of Building Construction and Planning Research, 3, 95-106. 


\section{Introduction}

\subsection{Background}

Public spaces are an important element of a vibrant and livable urban environment [1]. Good public spaces contribute to a wide range of benefits encompassing social, economic, and environmental spheres [2]. In an effort to provide quality public spaces, especially in densely developed urban areas, a unique type of public space was introduced, known as privately owned public space (POPS). POPS refers to publicly accessible and usable space that is developed and owned by private developers, in exchange for floor area bonuses and other concessions [3]. Since the introduction of privately owned public spaces in Korea in 1991, public-private partnerships have developed 1176 spaces in Seoul, totaling an area of 803,319 $\mathrm{m}^{2}$ [4]. Driven by real estate economics, POPSs are generally located in high-density urban areas having strong demands for additional floor area [3]. Because POPSs are widely diffused throughout the densely developed areas, they can benefit citizens by providing space for relaxation and social interaction. Therefore, these public open spaces have great potential to play significant roles as urban oases.

Apart from their quantitative success in Seoul, these spaces have been frequently criticized for the incompatibility between their intended role and actual uses. Critics often argue that, in Korea, the law provides a weak definition of the role and function of POPS and is thus responsible for the fact that the public, tenants of the host building, and developers lack an understanding of what constitutes POPS in an urban context [5]. Consequently, the provision of a POPS is considered merely a prerequisite for obtaining permission for a construction project [4], and POPSs are often deemed accessory spaces confined to the host building, rather than being viewed from a contextual perspective [6]. Insufficient consideration of the building lot's context often results in the creation of POPSs that frequently fail to interact with the surrounding urban context and even deteriorate urban environments [4] [6].

\subsection{Surrounding Context and Use of Public Space}

It is widely acknowledged that public spaces are context-sensitive [7]. They are strongly influenced by the surrounding physical, cultural, and environmental contexts. The diversity created by the interaction between different facilities with various uses around urban public space can add vitality to the space, and the ground floors of urban buildings are specifically more important as the ground floors have a greater impact on users than the rest of the building stories [8]. Commercial establishments on the ground floors of surrounding buildings, or sometimes even an existence of a small street vendor, effectively bring vitality to the public space [9]. Conversely, public spaces that are visited primarily by office workers are busy only at particular times of the day, normally during the lunch hour, leaving the space empty the rest of the day and often becoming smoking areas [10]. In this connection, New York City [11] encourages or restricts certain adjoining uses. Adjoining facilities cannot be occupied by uses that are considered unfavorable in encouraging the use of POPS such as banks or insurance offices. A certain portion of building frontage facing a POPS should be occupied by retail or service establishments on the ground floor level. It also provides installation and management rules for open air cafés or kiosks installed in POPSs. Moreover, the Special Zoning District takes a district-unit approach that can be used as a tool to take the characteristics of an area into account and selectively apply different standards to different districts if necessary.

However, according to the Building Act of Korea (2015) and Seoul's Municipal Building Ordinance (2015), the provision of POPS is determined by individual parcel units and the uses of adjoining or surrounding facilities are not considered. Developers of buildings in which more than $5000 \mathrm{~m}^{2}$ of floor space is used for certain purposes must create a POPS in their building lot. The mandatory area of the POPS varies from $5 \%$ to $10 \%$ of the building lots, depending on the total floor area of the host building. The only requirement concerning the surrounding context is that these spaces should face the broadest road adjacent to the lot. The issues discussed above, including a law that lacks due regard for the urban context and property owners who inadequately consider POPSs as accessory spaces confined to the host building, often result in spaces that fail to attain their expected goal [4].

Many domestic scholars have attempted to understand what factors affect the use of POPS (see Table 1). Kim [12] has extracted amenity indicators of POPS from a combination of interviews and surveys. These indicators have been popularly accommodated in subsequent researches in which certain variables proved influential to the 
Table 1. Components of POPS addressed in preceding researches.

\begin{tabular}{|c|c|c|}
\hline Research & & Variables \\
\hline \multirow{5}{*}{$\begin{array}{l}\text { Kim, S. } \\
(2002)\end{array}$} & Accessibility & $\begin{array}{l}\text { Configuration of space, segregation of pedestrian and vehicle, } \\
\text { conspicuousness of the main entrance of POPS, level difference obstacle }\end{array}$ \\
\hline & Openness & $\begin{array}{l}\text { Visual blockage, existence of stairs/slope/wall, } \\
\text { existence of signage/ventilation/electric installations, width of POPS }\end{array}$ \\
\hline & Convenience & Level of concentration of POPS, level of concentration of landscape, street furniture \\
\hline & Aesthetics & Type of landscape, width of landscaped area, public art \\
\hline & Management & Management condition, parking, flatness \\
\hline \multirow{3}{*}{$\begin{array}{l}\text { Song, J. } \\
\text { (2005) }\end{array}$} & User count & Total users, host building-related users, non-host building-related users, users $/ \mathrm{m}^{2}$ \\
\hline & $\begin{array}{c}\text { Locational } \\
\text { variables }\end{array}$ & $\begin{array}{l}\text { The number of accessible sides, distance from metro station, } \\
\text { bus stop, location characteristic on street system, local/global integration of adjacent street }\end{array}$ \\
\hline & $\begin{array}{l}\text { Non-locational } \\
\text { variables }\end{array}$ & $\begin{array}{l}\text { Total floor area of host building, area of public space, } \\
\text { configuration of space, use of ground floor facility of host building }\end{array}$ \\
\hline \multirow{7}{*}{$\begin{array}{l}\text { Jang, H. } \\
\text { (2006) }\end{array}$} & User count & Total users, host building-related users, non-host building-related users, total users $/ \mathrm{m}^{2}$ \\
\hline & Accessibility & $\begin{array}{l}\text { Configuration of space, the number of accessible sides, } \\
\text { distance from metro station, bus stop, and crosswalk }\end{array}$ \\
\hline & Openness & Width/depth of adjacent street, width of entrance, sky blockage ratio, side blockage ratio \\
\hline & Convenience & Seating, area of public space \\
\hline & Aesthetics & Landscaped area, environmental sculpture \\
\hline & Management & Flatness, management condition, number of pedestrians on adjacent street \\
\hline & Others & Total floor area of host building, use of ground level/underground facility of host building \\
\hline \multirow{4}{*}{$\begin{array}{l}\text { Im, D. } \\
(2014)\end{array}$} & User count & $\begin{array}{c}\text { Total users, host building-related users, non-host building-related users, } \\
\text { optional activity users, social activity users }\end{array}$ \\
\hline & $\begin{array}{l}\text { Physical } \\
\text { component }\end{array}$ & Shape and area of public space, configuration of public space \\
\hline & Accessibility & $\begin{array}{l}\text { Width of adjacent street, number of accessible sides, } \\
\text { distance from metro station/bus stop/crosswalk }\end{array}$ \\
\hline & Facility use & Use of ground floor facility of host building \\
\hline
\end{tabular}

use of POPS. These include the total floor area of the host building, area of POPS, type of business of underground facilities at the host building, configuration of POPS, flatness of the POPS floor, existence of a metro station or crosswalk, the width of adjoining sidewalk, and the length of seating [13] [14]. Other studies expanded the view and focused on the characteristics of adjacent streets or street network structure. They also analyzed their influence on the use of POPS and proposed design guidelines [6] [15]. These studies have effectively illustrated key principles necessary for getting the design of POPS right at the time of creation. Creating a POPS with the right design is undoubtedly critical to enhancing the quality of POPS because such tangible components create a physical stage in which subsequent features such as user activity and management can occur.

What was limited, however, was an interest on elements apart from the design of POPS, or the impacts coming from the outside the boundaries of POPS. Although the design of POPS is important, it has clear limitations in flexibly adjusting itself with respect to the rapidly changing urban environments because it hardly changes once it is created. Moreover, the users' perception on quality of POPS can be decisively determined by what comes after the design and the creation of POPS such as user activities, adjoining shop fronts at ground floor of the host building, or commercial facilities in surrounding areas. Given the nature of the POPS that is usually located in commercial/business districts, commercial facilities can, when properly managed, enliven moribund public spaces [16]. Despite the expected influences from surrounding facilities on the users, there has been a dearth of empirical research on the impact of the surroundings. Therefore, the intent of this study is to empirically verify the influence of surrounding facilities by measuring the association between constituent elements of POPS including surrounding ground floor facility use and the use of POPS using multiple regression analysis. 


\section{Methods}

\subsection{Study Sites}

The aim of this study can be best accomplished when conducted in an urban area with similar land use, favorably commercial areas in which POPSs are concentrated, and when POPSs in the area are surrounded by ground floor facilities with various uses. POPSs have been created intensively in and around three districts in Seoul: the central business district in the old downtown of Jongno-gu and Jung-gu; along Teheran Street in Gangnam-gu; and in Seoul Digital District in Guro-gu and Geumcheon-gu [17]. While all three districts meet most of the conditions listed above, we chose the central business district in Jongno-gu and Jung-gu, as the other two districts have relatively large building lots and POPSs in those districts were expected to be less sensitive to the influence of surroundings. According to the Seoul Open Space Register, an unpublished document that was personally provided to the authors by a city official, all POPSs located at the center of the old downtown area around Seoul City Hall were chosen. POPSs in the form of sidewalks were selectively excluded, due to their weak recognition as public spaces. Consequently, 48 POPSs were chosen and investigated (see Figure 1). The study area comprises different areas where various commercial/business uses are concentrated. These include streets offering food and cultural experiences (Da-dong and Mugyo-dong), others with large office buildings (Seosomun-dong and Shinmunro), and districts with high concentrations of retails, cafes, and restaurants (Myeong-dong and Namdaemun Market). The high concentration of POPSs and the surrounding buildings with various types of facilities on the ground floor qualify this area as appropriate for this study.

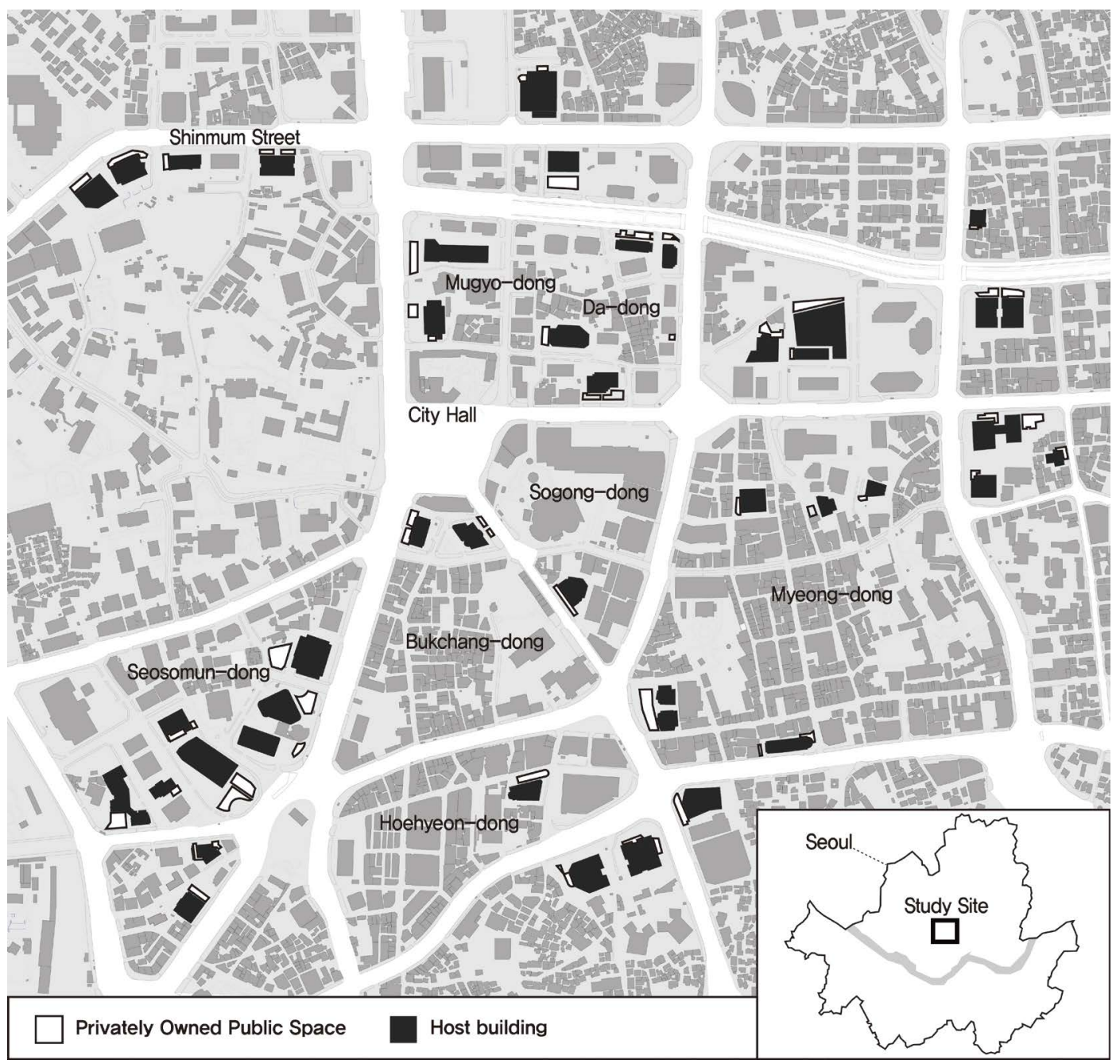

Figure 1. Study sites in Seoul. 


\subsection{Variables}

This study includes a set of variables that were typically not considered in previous Korean studies, namely the surrounding ground floor facility use. To clarify the definition of the surrounding ground floor facility use, we first defined the spatial range of the surrounding area, then the facility use. Defining spatial range of the surrounding area directly influencing the use of public space is based on how the level of human perception of urban environment varies by distance. The existence of facilities that can potentially promote the use of public spaces will be effective only when it is perceivable to potential users. Likewise, if the components of POPS used by previous studies to analyze what determines the use of POPS (e.g., accessibility, openness, convenience) are to be influential, they should be visually accessible for evaluation by potential users. Moreover, even when facilities promoting the use of public space exist within close proximity, the influence will be minimized if public space is physically isolated or inaccessible. In this sense, we concluded that the threshold of the area surrounding POPS is the distance from which the qualities of POPS and people using the space are discernible and easily accessible by a short walk. We referred to Gehl [18], who illustrated that at $20-25 \mathrm{~m}$ it is possible to communicate or read expressions and feelings, whereas $30 \mathrm{~m}$ is the distance at which people can still be perceived as individuals. However, although the 20 - $30 \mathrm{~m}$ threshold is applicable in some sections of Jongno-gu and Jung-gu where building lots are small, and both POPS and its surroundings are within $30 \mathrm{~m}$ radius, it is inappropriate in other sections, specifically along Sinmun Street and Namdaemun Street, as average parcel size far exceeds $30 \mathrm{~m}$. Therefore, considering that people walk about 50 - $60 \mathrm{~m}$ per minute, we defined a $50 \mathrm{~m}$ radius from the public space as the threshold of an influential surrounding area. The facility uses were categorized into one of three usage types according to the International Building Code's Use and Occupancy Classification, which includes assembly facility, mercantile facility, or business facility. Other uses such as educational, residential, or institutional uses were not found at the surrounding ground floor facilities of the chosen POPSs. An assembly facility is used to host gatherings for civic, social, or religious functions, for recreational purposes or to consume food and drinks, or while awaiting transportation. A mercantile facility is used for the display and sale of merchandise and involves stocks of goods, wares, or merchandise. Business facilities are used for lobbies, offices, and professional and/or service transactions. In short, the surrounding ground floor facility use measures the number of assembly, mercantile, and business uses at the ground floor facilities within a $50 \mathrm{~m}$ radius from POPS.

Excluding the surrounding ground floor facility use, all other independent variables used in multiple regression analysis were derived from literature on the use of public space [12]-[15]. Table 2 shows variables used to build regression models.

\subsection{User Count}

Given that the study area is a central business district with diverse commercial and business facilities but few residential facilities, we expected that it would be vibrant during weekdays but quiet on weekends. Therefore, we expected that the use of POPSs on weekdays would be associated with different variables than on weekends. Whereas previous research in Korea analyzed POPSs based on weekday users, we quantified both weekday and weekend users.

\subsection{Data}

Data used in the analysis were collected from three sources: the Seoul Open Space Register from which information on total floor area of host buildings and area of POPSs were acquired; an online map service provided by a website [19] from which distances from a metro station, bus stop, and crosswalk were investigated; and on-site observations and measurements providing information on the use of surrounding ground floor facilities, configuration, accessible sides, level difference, and user count. The user observation was conducted on clear days with moderate temperatures in October. The photographs of each POPS were taken four times a day when the spaces were expected to be intensively used: between 12-1 p.m., 1-2 p.m. (during and after the lunch hours), 5-6 p.m., and 6-7 p.m. (general closing hour of offices). The number of individuals shown in the photographs taken over the course of a day was combined to calculate the user count. The photographs were taken on both weekdays and weekends. People who simply passed through a space were excluded from the data, because of the weak linkage between design components and the use of the space [18]. 
Table 2. Variables used in this analysis.

\begin{tabular}{|c|c|c|}
\hline Variable (abbreviation) & & \\
\hline Assembly facility (AF) & Number of assembly facilities within $50 \mathrm{~m}$ & \multirow{6}{*}{ Continuous variables } \\
\hline Mercantile facility (MF) & Number of mercantile facilities within $50 \mathrm{~m}$ & \\
\hline Business facility (BF) & Number of business facilities(including lobby) within $50 \mathrm{~m}$ & \\
\hline Total floor area (TFA) & Total floor area of the host building of POPS $\left(\mathrm{m}^{2}\right)$ & \\
\hline Area of POPS (AREA) & Area of privately owned public space $\left(\mathrm{m}^{2}\right)$ & \\
\hline Seating (SEAT) & Length of all seating combined (cm) & \\
\hline Configuration (CONFIG) & Location of POPS relative to the host building's entrance & $\begin{array}{c}\text { Binary variable: } \\
\text { Front/corner }=1 \text { (more accessible) } \\
\text { Side/rear }=0 \text { (less accessible) }\end{array}$ \\
\hline Accessible sides (SIDE) & $\begin{array}{l}\text { The number of roads or sidewalks open } \\
\text { to and accessible from the public space }\end{array}$ & Ranges from 1 to 3 \\
\hline Level difference (LEVEL) & $\begin{array}{l}\text { Vertical difference between public } \\
\text { space and adjacent public access (cm) }\end{array}$ & Continuous variable \\
\hline Metro station (METRO) & $\begin{array}{l}\text { Existence of metro station within } 50 \mathrm{~m} \\
\quad \text { (one minute walking distance) }\end{array}$ & \multirow{3}{*}{$\begin{array}{l}\text { Binary variables: } \\
\text { Yes }=1 \\
\text { No }=0\end{array}$} \\
\hline Bus stop (BUS) & Existence of bus stop within $50 \mathrm{~m}$ (one minute walking distance) & \\
\hline Crosswalk (CROSS) $^{*}$ & $\begin{array}{l}\text { Existence of crosswalk within } 20 \mathrm{~m} \\
\text { (distance close enough to reach } \\
\text { crosswalk as the traffic light changes) }\end{array}$ & \\
\hline Weekday user count & $\begin{array}{l}\text { The number of all POPS users observed } \\
\text { over the course of one weekday }\end{array}$ & \multirow{2}{*}{ Continuous variables } \\
\hline Weekend user count & $\begin{array}{l}\text { The number of all POPS users observed } \\
\text { over the course of one weekend day }\end{array}$ & \\
\hline
\end{tabular}

${ }^{*}$ Crosswalk included pedestrian underpasses. In the study site are many pedestrian underpasses connecting blocks that are severed by arterial roads in place of crosswalks. Short crosswalks without traffic lights were also excluded.

\section{Analysis}

\subsection{Descriptive Statistics}

The sum of all weekday users was roughly 2.3 times larger than the sum of all weekend users. The deviation of the weekend user count was larger than that of weekday user count. Judging by the average and the standard deviation, the BF was more evenly distributed than AF or MF. Table 3 shows descriptive statistics of all variables.

\subsection{Multiple Regression Analysis}

Prior to conducting multiple regression analysis, we conducted correlation analysis to prevent a multicollinearity problem. Assembly and business facilities were in high correlation (0.662). However, considering the importance of the variables, we decided to retain both of them. With the exception of correlation between assembly facility and business facility, correlation coefficients were lower than 0.6. No multicollinearity problem was evident (see Table 4), we incorporated all 12 independent variables, and conducted multiple regression analysis using SPSS 18.0. The enter method that inputs all independent variables simultaneously into the regression was used in this study because the effect of diverse variables addressed in previous studies varied by case.

Analysis of both Model-1 (dependent variable: weekday user count, $\mathrm{R}^{2}=0.591, \mathrm{P}<0.001$ ) and Model-2 (dependent variable: weekend user count, $\mathrm{R}^{2}=0.880, \mathrm{P}<0.001$ ) were performed. Tolerance values for all variables in the two models were larger than 0.1 and variance inflation factor (VIF) less than 10 , which means no multicollinearity problem was found. Table 5 shows the results of multiple regression analysis.

In Model-1, four variables were found to be determinants of the use of POPS. Standardized coefficients suggested that the contribution of variables to the use of POPS is in the order of BF $(-0.498)$, AF $(0.444)$, 
Table 3. Descriptive statistics of the variables $(N=48)$.

\begin{tabular}{cccccc}
\hline & Total & Average (SD) & Median & Mode & Min/max \\
\hline AF & 231 & $4.8(6.5)$ & 2.5 & 0 & $0 / 24$ \\
MF & 81 & $1.7(3.4)$ & 0 & 0 & $0 / 21$ \\
BF & 114 & $2.4(1.3)$ & 2.0 & 2.0 & $1 / 6$ \\
TFA & 2940235.6 & $61254.9(35953.2)$ & 55503.5 & 37799.6 & $7646.5 / 168050.0$ \\
AREA & 19515.9 & $406.6(362.4)$ & 282.0 & 469.4 & $48.9 / 1752.3$ \\
SEAT & 138155.3 & $2878.2(3113.1)$ & 2214.0 & 900 & $0 / 19332$ \\
CONFIG & 29 & $0.6(0.5)$ & - & - & - \\
SIDE & 80 & $1.7(0.7)$ & 2 & 1 & $0 / 3$ \\
LEVEL & 2111 & $44.0(78.3)$ & 8 & 0 & $0 / 1$ \\
METRO & 5 & $0.1(0.3)$ & 0 & 0 & $0 / 1$ \\
BUS & 15 & $0.3(0.5)$ & 0 & 0 & $0 / 1$ \\
CROSS & 15 & $0.3(0.5)$ & 0 & 0 & $0 / 180$ \\
Weekday user count & 2256 & $47(49.1)$ & 25.5 & 20 & $0 / 181$ \\
(Model-1) & 990 & $20.6(33.8)$ & 10 & 0 & \\
Weekend user count & & & & \\
(Model-2) & 5 & & & & 0 \\
\hline
\end{tabular}

Table 4. Results of correlation analysis.

\begin{tabular}{|c|c|c|c|c|c|c|c|c|c|c|c|c|}
\hline & $\mathrm{AF}$ & MF & $\mathrm{BF}$ & TFA & AREA & SEAT & CONFIG & SIDE & LEVEL & METRO & BUS & CROSS \\
\hline \multicolumn{13}{|l|}{$\mathrm{AF}$} \\
\hline MF & 0.463 & & & & & & & & & & & \\
\hline $\mathrm{BF}$ & 0.662 & 0.209 & & & & & & & & & & \\
\hline TFA & -0.203 & -0.206 & -0.208 & & & & & & & & & \\
\hline AREA & 0.105 & -0.076 & 0.052 & 0.499 & & & & & & & & \\
\hline SEAT & -0.013 & 0.135 & -0.100 & 0.253 & 0.538 & & & & & & & \\
\hline CONFIG & 0.003 & 0.113 & -0.106 & 0.050 & 0.204 & 0.201 & & & & & & \\
\hline SIDE & 0.213 & 0.076 & 0.125 & 0.334 & 0.374 & $0.346^{*}$ & -0.020 & & & & & \\
\hline LEVEL & -0.233 & -0.134 & -0.069 & 0.005 & -0.095 & -0.045 & -0.219 & -0.355 & & & & \\
\hline METRO & 0.063 & 0.071 & 0.219 & 0.011 & -0.146 & -0.115 & -0.003 & 0.159 & -0.056 & & & \\
\hline BUS & -0.162 & -0.175 & -0.045 & 0.426 & 0.013 & -0.194 & 0.178 & 0.000 & 0.080 & 0.064 & & \\
\hline CROSS & -0.190 & -0.240 & -0.011 & $0.326^{*}$ & 0.428 & 0.361 & 0.178 & 0.251 & -0.028 & -0.083 & -0.164 & \\
\hline
\end{tabular}

(Bold): $\alpha<0.01$; (Italic): $\alpha<0.05$.

Table 5. Results of multiple regression analysis.

\begin{tabular}{ccccccccc}
\hline & \multicolumn{2}{c}{ Model-1 (weekday) $\left(\mathrm{N}=48, \mathrm{R}^{2}=0.591, \mathrm{P}<0.001\right)$} & \multicolumn{4}{c}{ Model-2 (weekend) $\left(\mathrm{N}=48, \mathrm{R}^{2}=0.880, \mathrm{P}<0.001\right)$} \\
\cline { 2 - 8 } & $\mathrm{b}$ & $\mathrm{BETA}$ & $\mathrm{P}$ & VIF & $\mathrm{b}$ & BETA & $\mathrm{P}$ & VIF \\
\hline $\mathrm{C}$ & 57.314 & & 0.017 & & 11.832 & & 0.176 & \\
$\mathrm{AF}$ & $\mathbf{3 . 3 6 1}$ & $\mathbf{0 . 4 4 4}$ & $\mathbf{0 . 0 1 9}$ & $\mathbf{2 . 7 8 3}$ & 0.479 & 0.092 & 0.353 & 2.783 \\
$\mathrm{MF}$ & $\mathbf{5 . 8 3 5}$ & $\mathbf{0 . 4 1 2}$ & $\mathbf{0 . 0 0 4}$ & $\mathbf{1 . 5 2 6}$ & $\mathbf{8 . 2 0 4}$ & $\mathbf{0 . 8 4 1}$ & $\mathbf{0 . 0 0 0}$ & $\mathbf{1 . 5 2 6}$ \\
\hline
\end{tabular}




\begin{tabular}{cccccccccc} 
Continued & \multicolumn{10}{c}{} & & & & & & \\
\hline BF & $\mathbf{- 1 8 . 4 0 6}$ & $\mathbf{- 0 . 4 9 8}$ & $\mathbf{0 . 0 0 5}$ & $\mathbf{2 . 3 4 4}$ & $\mathbf{- 8 . 0 4 5}$ & $\mathbf{- 0 . 3 1 6}$ & $\mathbf{0 . 0 0 1}$ & $\mathbf{2 . 3 4 4}$ \\
TFA & 0.000 & -0.066 & 0.694 & 2.347 & 0.000 & -0.060 & 0.507 & 2.347 \\
AREA & $\mathbf{0 . 0 4 9}$ & $\mathbf{0 . 3 6 1}$ & $\mathbf{0 . 0 3 1}$ & $\mathbf{2 . 2 1 0}$ & $\mathbf{0 . 0 2 3}$ & $\mathbf{0 . 2 4 3}$ & $\mathbf{0 . 0 0 8}$ & $\mathbf{2 . 2 1 0}$ \\
SEAT & 0.001 & 0.039 & 0.793 & 1.821 & 0.000 & 0.012 & 0.875 & 1.821 \\
CONFIG & -8.896 & -0.089 & 0.498 & 1.463 & 4.928 & 0.072 & 0.316 & 1.463 \\
SIDE & 0.796 & 0.012 & 0.934 & 1.718 & 1.175 & 0.025 & 0.745 & 1.718 \\
LEVEL & 0.058 & 0.093 & 0.460 & 1.324 & 0.017 & 0.039 & 0.568 & 1.324 \\
METRO & 21.959 & 0.138 & 0.253 & 1.205 & $\mathbf{2 4 . 8 7 4}$ & $\mathbf{0 . 2 2 7}$ & $\mathbf{0 . 0 0 1}$ & $\mathbf{1 . 2 0 5}$ \\
BUS & -14.712 & -0.140 & 0.352 & 1.892 & -8.023 & -0.111 & 0.176 & 1.892 \\
CROSS & -17.083 & -0.163 & 0.273 & 1.827 & -1.065 & -0.015 & 0.853 & 1.827
\end{tabular}

(Bold): $\alpha<0.05$; (Italic): $\alpha<0.1$.

MF (0.412), and AREA (0.361). Thus, when fewer BF exist, more AF exist, more MF exist, or AREA increases, indicating that more users visited the space. The coefficients of BF, MF, AF, and AREA were -18.406, 5.835, 3.361, and 0.049 , respectively. These represent the mean change in user count for one unit of change in the independent variable while holding other independent variables in the model constant. For example, when the values of other variables are consistent, the one unit of increase in the number of MF increased the number of users by 5.8. Similarly, one unit of increase in the number of AF increased the number of users by 3.4. On the other hand, an increase in the number of BF by one unit decreased the number of users by 18.4. The increase of $1 \mathrm{~m}^{2}$ in AREA increased the number of users by 0.05 .

In Model-2, four variables including MF, BF, AREA, and METRO were found to be determinants of the use of POPS. The standardized coefficients of these four variables indicated the order of contribution to the use of POPS as MF (0.841), BF ( -0.316$)$, AREA (0.243), and METRO (0.227). The coefficients were following: MF (8.204), BF (-8.045), AREA (0.023), and METRO (24.874). This shows that one unit of increase in the number of MF increased the number of users by 8.2 and the existence of a METRO increased the number of users by 24.874. The $1 \mathrm{~m}^{2}$ increase in AREA raised the number of users by 0.02 . Conversely, one unit of increase in the number of BF decreased the number of users by 8 .

\subsection{Multiple Regression Analysis with Divided POPS Groups}

Due to the overriding influence of the surrounding ground floor facility use, secondary factors that may affect the use of POPSs are unclear. To clarify these secondary factors, we divided 48 POPSs into two groups by comparing the numbers of commercial facilities (assembly and mercantile facilities combined) and business facilities. First, the numbers of assembly and mercantile facilities were combined to calculate the overall number of commercial facilities. Then, the number of business facilities was subtracted from the number of commercial facilities. If the difference was positive, indicating more commercial facilities than business facilities, it was assigned to the group of POPSs surrounded by commercial facilities; if the difference was negative it was assigned to the other group. When the difference was zero, it was assigned to the group surrounded by business facilities because the regression analysis of Model-1 and Model-2 showed that the coefficient of business facility was similar or larger than mercantile or assembly facilities, depending on days of the week. As a result, 48 POPSs were divided into groups surrounded by commercial facilities and surrounded by business facilities (see Table 6). The same multiple regression analysis was used with each group.

First, the multiple regression analysis using the sample of 25 POPSs surrounded by commercial facilities was conducted. Model-3 (dependent variable: weekday user count, $\mathrm{R}^{2}=0.803, \mathrm{P}=0.011$ ) and Model-4 (dependent variable: weekend user count, $\mathrm{R}^{2}=0.960, \mathrm{P}<0.001$ ) were performed by the enter method. Tolerance values for all variables in the two models were larger than 0.1 and VIF less than 10 , which means no multicollinearity problem was evident. Table 7 shows the results of multiple regression analysis.

In the case of Model-3, three variables were found to be determinants of the use of POPS at the significance 
Table 6. Descriptive statistics of divided groups.

\begin{tabular}{|c|c|c|c|c|}
\hline \multirow{2}{*}{ Variables } & \multicolumn{2}{|c|}{ POPS surrounded by commercial facilities $(\mathrm{N}=25)$} & \multicolumn{2}{|c|}{ POPS surrounded by business facilities $(\mathrm{N}=23)$} \\
\hline & Total & Average (SD) & Total & Average (SD) \\
\hline $\mathrm{AF}$ & 210 & $8.4(7.3)$ & 21 & $0.9(1.0)$ \\
\hline MF & 77 & $3.1(4.4)$ & 4 & $0.2(0.5)$ \\
\hline $\mathrm{BF}$ & 65 & $2.6(1.6)$ & 48 & $2.0(0.9)$ \\
\hline TFA & 1480029.4 & $59201.2(38646.3)$ & 1460206.1 & $63487.2(33499.7)$ \\
\hline AREA & 10278.8 & $411.2(416.2)$ & 9237.0 & $401.6(302.6)$ \\
\hline SEAT & 70614.3 & $2824.6(2310.3)$ & 67541.0 & $2936.6(3856.9)$ \\
\hline CONFIG & 14 & $0.6(0.5)$ & 15 & $0.7(0.5)$ \\
\hline SIDE & 46 & $1.8(0.7)$ & 34 & $1.5(0.5)$ \\
\hline LEVEL & 615 & 24.6 (32.0) & 1496.0 & $65.0(105.4)$ \\
\hline METRO & 3 & $0.1(0.3)$ & 2 & $0.1(0.3)$ \\
\hline BUS & 7 & $0.3(0.5)$ & 8 & $0.3(0.5)$ \\
\hline CROSS & 6 & $0.2(0.4)$ & 9 & $0.4(0.5)$ \\
\hline $\begin{array}{l}\text { Weekday user count } \\
\text { (Model-3, 5) }\end{array}$ & 1770 & 70.8 (57.4) & 486 & $21.1(14.8)$ \\
\hline $\begin{array}{l}\text { Weekend user count } \\
\text { (Model-4, 6) }\end{array}$ & 790 & $31.6(43.7)$ & 200 & $8.7(8.4)$ \\
\hline
\end{tabular}

Table 7. Results of multiple regression analysis of POPS surrounded by commercial facilities.

\begin{tabular}{|c|c|c|c|c|c|c|c|c|}
\hline & \multicolumn{4}{|c|}{$\begin{array}{l}\text { Model-3: weekday user count } \\
\left(\mathrm{N}=25, \mathrm{R}^{2}=0.803, \mathrm{P}=0.011\right)\end{array}$} & \multicolumn{4}{|c|}{$\begin{array}{l}\text { Model-4: weekend user count } \\
\left(\mathrm{N}=25, \mathrm{R}^{2}=0.960, \mathrm{P}<0.001\right)\end{array}$} \\
\hline & $\mathrm{b}$ & BETA & $\mathrm{P}$ & VIF & $\mathrm{b}$ & BETA & $\mathrm{P}$ & VIF \\
\hline $\mathrm{C}$ & 24.252 & & 0.545 & & -4.389 & & 0.749 & \\
\hline $\mathrm{AF}$ & 1.327 & 0.169 & 0.565 & 4.986 & 0.111 & 0.019 & 0.888 & 4.986 \\
\hline MF & 2.713 & 0.206 & 0.262 & 1.870 & 7.323 & 0.731 & 0.000 & 1.870 \\
\hline $\mathrm{BF}$ & -15.362 & -0.423 & 0.141 & 4.375 & -8.455 & -0.306 & 0.027 & 4.375 \\
\hline TFA & 0.000 & 0.159 & 0.510 & 3.313 & 0.000 & 0.115 & 0.299 & 3.313 \\
\hline AREA & 0.065 & 0.469 & 0.058 & 3.031 & 0.033 & 0.314 & 0.009 & 3.031 \\
\hline SEAT & 0.003 & 0.136 & 0.630 & 4.613 & 0.000 & 0.010 & 0.938 & 4.613 \\
\hline CONFIG & 10.582 & 0.093 & 0.698 & 3.347 & 15.457 & 0.179 & 0.117 & 3.347 \\
\hline SIDE & 20.707 & 0.269 & 0.307 & 3.867 & 9.409 & 0.161 & 0.185 & 3.867 \\
\hline LEVEL & 0.210 & 0.117 & 0.601 & 2.883 & -0.031 & -0.023 & 0.820 & 2.883 \\
\hline METRO & 46.749 & 0.270 & 0.141 & 1.784 & 40.613 & 0.308 & 0.002 & 1.784 \\
\hline BUS & -63.287 & -0.505 & 0.063 & 3.697 & -33.742 & -0.354 & 0.008 & 3.697 \\
\hline CROSS & -84.039 & -0.638 & 0.064 & 5.962 & -32.822 & -0.327 & 0.039 & 5.962 \\
\hline
\end{tabular}

(Bold): $\alpha<0.05 ;$ (Italic): $\alpha<0.1$. 
level of $\mathrm{P}<0.1$. Standardized coefficients of the three variables included CROSS $(-0.638)$, BUS $(-0.505)$, and AREA (0.469). This means that if the AREA increased, the more users visited the space. The existence of a nearby crosswalk or bus stop decreased the number of people. The coefficients of CROSS, BUS, and AREA were $-84.039,-63.287$, and 0.065 , respectively. Thus, with the existence of a crosswalk within $50 \mathrm{~m}$, the number of users decreased by 84 , and the existence of a bus stop decreased the number of users by 63.2. Conversely, a $1 \mathrm{~m}^{2}$ increase in AREA increased the number of users by 0.07 .

In Model-4, six variables were proven to be determinants. Among the six variables, the standardized coefficient of MF (0.731) was the largest, followed by BUS (-0.354), CROSS ( -0.327$)$, AREA (0.314), METRO (0.308), and BF (-0.306). The following coefficients were determined: MF (7.323), BUS (-33.742), CROSS (-32.822), AREA (0.033), METRO (40.613), and BF (-8.455).

However, analysis using the sample of 23 POPSs surrounded by business facilities showed problems in model significance probability. Both Model-5 (dependent variable: weekday user count, $\mathrm{P}=0.730$ ) and Model-6 (dependent variable: weekday user count, $\mathrm{P}=0.185$ ) were not statistically significant.

Regarding surrounding ground floor facility use, all four models except Model-3 showed that MF had a decisively strong relationship with the user count, especially on weekends. The MF such as convenient stores, clothing stores, mobile phone shops, or cosmetic shops can attract potential POPS users that often lead to actual uses. Especially on weekends, many of the populations in the study site were presumably doing recreational activities such as shopping or dating, and mercantile facilities can be their destinations. On the other hand, AF was one of the determinants positively associated with the weekday user count in Model-1, whereas it was not associated with the weekend user count in Model-2. Noting that BF and AF were in high correlation $(r=0.662)$, it is possible to assume that many of assembly facilities were located at or proximate to business facilities. In that sense, on weekdays, POPSs having some assembly facilities in its surroundings seemed to be used by workers from the office facilities nearby. On weekends when many office facilities close, the overall number of office workers in the area declined and accordingly so did the use of POPSs with assembly facilities in the surroundings, leading to the exclusion of AF from Model-3 (see Figure 2). This interpretation also corresponds to the result of previous research indicating that approximately $40 \%-70 \%$ of POPS users were host building employees [13]-[15]. Additionally, interpreting the negativity of the BF coefficient can easily be misleading because the lobbies on the ground floor were also counted as BF. Considering that all but four of the host buildings in the study site are office buildings and had lobbies on the ground floor level, it is more plausible to interpret the negative coefficient of BF as a concentration of office buildings without commercial facilities on the ground floor leading to fewer users of POPS.

Other variables in favor of promoting the use of POPS were the existence of a metro station within $50 \mathrm{~m}$ from POPS. However, while AREA was a determinant for the user count in all four models, the coefficients for AREA were small and the rate of change of the user count with respect to alteration of AREA can hardly be substantial in terms of cost-efficiency. Moreover, according to the Building Act of Korea, the area of POPS is determined by the total floor area of the host building and the area of the building lot. The area of POPS is much
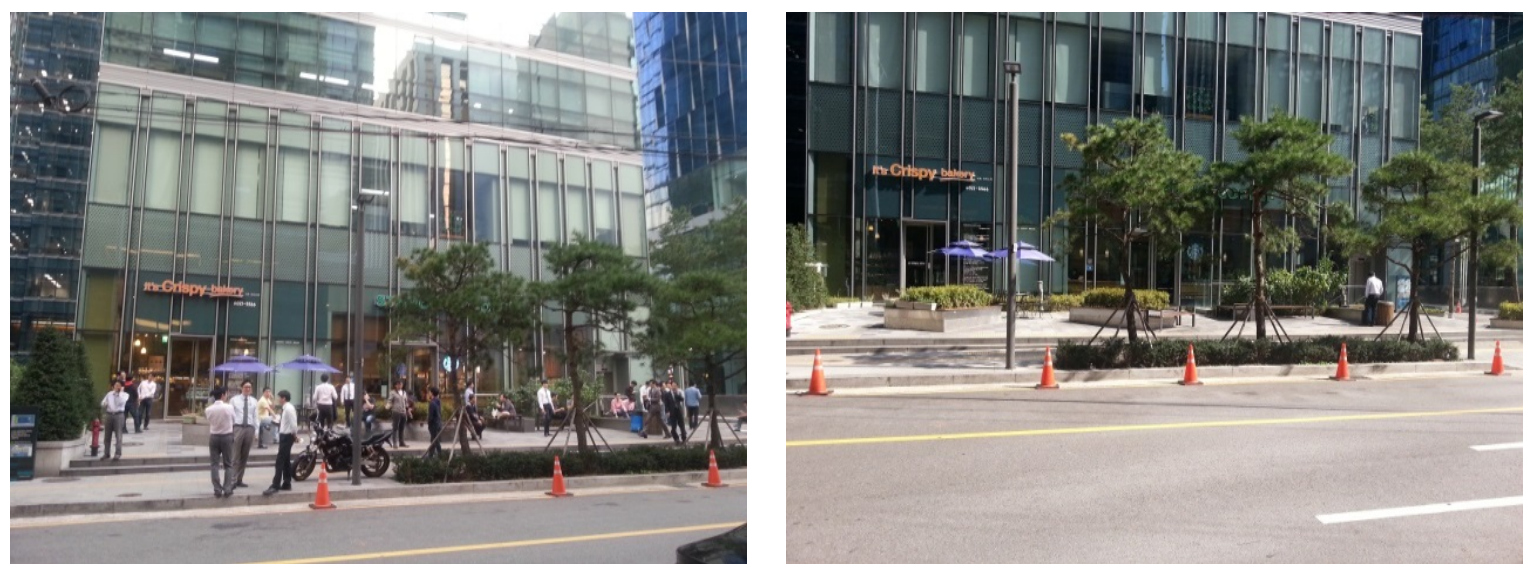

Figure 2. A POPS located in front of an office building with assembly facilities at the ground floor (left: weekday, right: weekend). 
less flexible than other elements that affect the use of POPS, and the effect of improvement plan to elevate the use of POPSs by providing more spacious space is expected to be less efficient.

The negative coefficient of BUS and CROSS shown in Model-3 and Model-4 can be understood in regard to the study site's characteristics. The study site's urban fabric is segmented by wide arterial roads, and crosswalks, pedestrian underpasses, and bus stops were primarily located along the arterials. Thus, the negativity of coefficient can be explained as POPSs sitting along the arterial roads were less favored than those at the inner locations of a block.

To summarize, the number of weekend users (Model-1) was associated with all three uses of surrounding ground floor facility: assembly, mercantile, and business. The number of weekend users (Model-2) was associated with MF, BF, and METRO. The AREA related to the number of users regardless of the models. The analysis of divided groups revealed that the number of weekday users in POPSs surrounded by commercial facilities (Model-3) was negatively associated with a bus stop or crosswalk. The number of weekend users in this group (Model-4) was positively associated with MF and METRO, whereas the existence of a bus stop and crosswalk had negative relationships with the number of users. Model-5 and Model-6 used POPSs surrounded by business facilities and showed inappropriate significance reliability.

\section{Conclusions and Discussion}

Results of this study suggest that although the quality of constituent elements of POPS is undoubtedly important for encouraging the use of spaces, it is even more critical to locate POPS in the appropriate urban context. Because the use of POPS is decisively influenced by the uses of surrounding ground floor facilities, it is critical to understand how POPS and its surroundings interact and influence each other. This is strongly underpinned by the multiple regression analysis results. Additionally, the POPSs surrounded by commercial facilities were used 3.6 to 4.0 times more frequently than those surrounded by business facilities, depending on days of the week. The provision and design standards can adopt criteria that evaluate the distribution of ground floor facility uses in different districts, ideally in smaller units of space than by district. They could also designate the locations of POPSs accordingly. Moreover, differentiated incentives can be applied to the host buildings of POPS to encourage the installation of favorable facilities, ideally mercantile facilities, on the ground floor of the host building, or to locate POPS near existing commercial facilities nearby.

Additionally, this research suggests that if supported by future studies, the use of POPS can be anticipated by investigating the preexisting urban context at a given location. For example, POPS surrounded by abundant mercantile and assembly facilities and with good access to the metro station are expected to be actively used by not only the office workers but also by other classes of society regardless of days of the week. Conversely, POPS surrounded primarily by office facilities are likely to be used by a small number of office workers, and the use is expected to be concentrated on weekdays. Differentiated design guidelines supporting these anticipated patterns of uses can promote the benefits of POPS and reduce the elements that deteriorate the experience of using them. Further studies addressing detailed patterns of the use of POPS and a more comprehensive analysis framework directed at various elements of the surrounding urban context of POPS other than the facility use are required.

The fact that commercial facilities have substantial influence in promoting the use of POPS also increases the need for emphasizing the management of POPS. Critics have frequently discussed the risk of public spaces being privatized and commodified, especially those owned and managed by the private sector [16] [20]. Németh [1] has illustrated that transforming public spaces into consumption spaces is often done by private interests invading the public space, most often by restaurants and cafés (i.e., assembly facilities). This commercial spillover was observed in three POPSs in our study sites as well, often in the form of café creep. These spaces were distinctively popular and full of users, but at the same time their publicness was questionable [10]. Considering New York City's experience, an adequate balance between accommodating benefits of the commercial facilities and securing the publicness is required.

This study has several limitations. First, the analysis was performed based on the data acquired from a particular area in Seoul's downtown. The results may represent characteristics of the study site and are thus hard to generalize. Second, the observation of users was conducted over a short time period. The use of POPS that may vary by assorted seasonal and climatic conditions was not considered. Third, other various elements comprising characteristics of the surrounding context of POPS were excluded. This topic therefore requires further research with more comprehensive and rigorous methodologies. 


\section{References}

[1] Németh, J. (2009) Defining a Public: Managing Privately Owned Public Space. Urban Studies, 46, 2463-2490. http://dx.doi.org/10.1177/0042098009342903

[2] Carmona, M., Claudio, M. and Leo, H. (2008) Public Space: The Management Dimension. Routledge, New York.

[3] Kayden, J.S. (2000) The New York City Department of City Planning and the Municipal Art Society of New York. Privately Owned Public Space: The New York City Experience. John Wiley \& Sons, Inc., New York.

[4] Lee, S. and Kim, Y. (2012) Improvement of System on Privately Owned Public Space for Elevating the Quality of Urban Public Spaces (Report No. 2012-6). Architecture and Urban Research Institute, Anyang.

[5] Kim, H. (2000) A Study of Utilization of Semi-Public Space of Street for the Betterment in Life Environment. Journal of the Korean Housing Association, 11, 85-95.

[6] Park, J. (2011) Development of Design Guideline for the Use Enhancement of Privately Owned Public Space (Unpublished Doctoral Dissertation). Korea University, Seoul.

[7] Jacobs, J. (1961) The Death and Life of Great American Cities. Vintage, New York.

[8] Gehl, J., Kaefer, L.J. and Reigstad, S. (2006) Close Encounters with Buildings. Urban Design International, 11, 29-47. http://dx.doi.org/10.1057/palgrave.udi.9000162

[9] Whyte, W.H. (1980) The Social Life of Small Urban Spaces. Conservation Foundation, Washington DC.

[10] Koo, B. (2013) Classification of User Behavior in Privately Owned Public Space According to the Building Use (Unpublished Master's Dissertation). Seoul National University, Seoul.

[11] New York City Planning. http://www.nyc.gov/html/dcp/html/priv/priv.shtml

[12] Kim, S. (2002) A Study on The Amenity Indicator of Office Public Space. Journal of Architectural Institute of Korea, 18, 147-154.

[13] Jang, H. and Lee, I. (2006) A Study on the Effect of Factors on the Use of Private-Owned Pocket Parks. Journal of Urban Design Institute of Korea, 7, 47-60.

[14] Im, D., Park, C. and Koo, J. (2014) A Study on Relationship between Physical Components of Public Open Space Owned by Private Sector and Behaviour Types of User. Journal of Urban Design Institute of Korea, 15, 79-90.

[15] Song, J. (2005) Effect of Location Factors on the Use of Public Open Spaces. Unpublished Master’s Dissertation, Seoul National University, Seoul.

[16] Kayden, J. (2005) Using and Misusing Law to Design the Public Realm. In: Ben-Joseph, E. and Szold, T., Eds., Regulating Place: Standards and the Shaping of Urban America, Routledge, New York, 115-140.

[17] Choi, S. (2013) A Study on the Privately-Owned Public Spaces of Guro Digital Complex as an Apparatus for Urban Public Environment. Unpublished Master’s Dissertation, Seoul National University, Seoul.

[18] Gehl, J. (1987) Life between Buildings: Using Public Space. Van Nostrand Reinhold Company, New York.

[19] Daum Map. http://maps.daum.net

[20] Lee, J., Kim, S. and Park, Y. (2008) A Study on the Privatization of Public Open Space in Urban Commercial Strip Buildings. Journal of Architectural Institute of Korea, 28, 257-260. 